\title{
Banach and Nikodym on the Bench in Kraków Again
}

Danuta Ciesielska (Institute for the History of Science, Polish Academy of Sciences, Warsaw, Poland) and Krzysztof Ciesielski (Jagiellonian University, Kraków, Poland)

Sometimes accidental events have a huge impact on history. One such event took place 100 years ago. An evening walk of a 29-year-old mathematician resulted in the "discovery" of an extremely talented mathematician and, consequently, several outstanding results in mathematics. This meeting has recently been commemorated in Kraków.

\section{Steinhaus}

Let us start with an introduction of Hugo Steinhaus (1887-1972). He studied in Göttingen, where, in 1911, he obtained his PhD under the supervision of David Hilbert. He was an exceptional person with a broad knowledge of different branches of mathematics. A significant part of his scientific work involves practical, sometimes very surprising, applications of mathematics. He was remarkably multi-faceted and was a man of great culture and deep knowledge of literature. His aphorisms, remarks and thoughts are famous to this day. Unfortunately, most of them, including the best, are not translatable. One of his thoughts was: "It is easy to go from the house of reality to the forest of mathematics, but only few know how to go back." Once, when somebody was decorated with a medal, Steinhaus said: "Now I know what to do in order to be awarded a medal. Nothing, but for a very long time." He used to say that "a computer is an extremely efficient idiot". He was an accomplished populariser of mathematics. His book "Mathematical Snapshots", first published in 1938, was translated into many languages. However, in the second decade of the 20th century, he was just a young, well-educated mathematician without an occupation. In the Summer of 1916, in the middle of World War I, Hugo Steinhaus was spending some months in Kraków. This Polish city was then a safe fortress in the Austro-Hungarian empire.

\section{A famous meeting}

Once, during his evening walk in the Planty Gardens in the centre of Kraków, Steinhaus heard the words "Lebesgue integral". At that time, this was a recent idea known almost exclusively to specialists. Steinhaus was intrigued. He joined the conversation between two young men, who turned out to be Stefan Banach and Otton Nikodym. They told Steinhaus that they had a habit of evening walks and discussing mathematics. In fact, they were usually talking about mathematics with their friend Witold Wilkosz but, this evening, Wilkosz was not with them. During the conversation, Steinhaus presented a problem he was currently working on. The problem concerned the convergence in the first moment of partial sums of the

Fourier series of an integrable function. A few days later, Banach visited Steinhaus and presented to him a correct solution of the problem. Then, Steinhaus realised that Banach had an incredible mathematical talent. He started taking care of Banach. The solution of this problem was published in the Bulletin International de l'Académie Sciences de Cracovie [3], presented by Stanisław Zaremba (1863-1942), the most well known Polish mathematician of that period. Later, Steinhaus, an author of many important papers, used to say that his best mathematical discovery was the "discovery" of Stefan Banach.

\section{Banach, Nikodym and Wilkosz before 1916}

Who were the three young men who had a habit of evening discussions about mathematics? Let us start with the most famous of them, Stefan Banach.

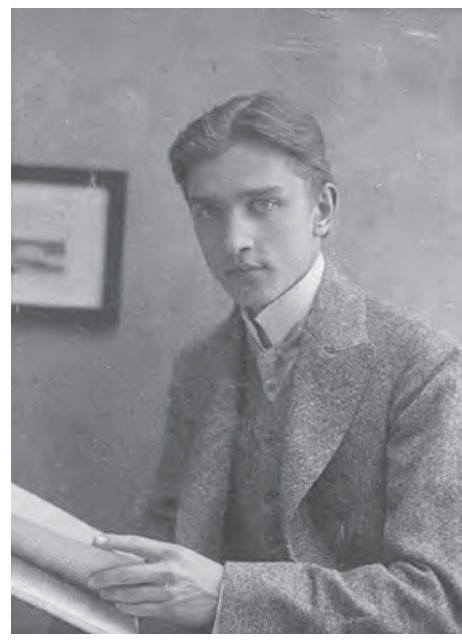

Figure 1. Stefan Banach in 1919. (Courtesy of the Banach family collection [11]).
Banach was born in Kraków in 1892. He was born out of wedlock and took his surname from his mother, Katarzyna Banach. His father, Stefan Greczek, was a soldier serving in the Austrian army. Entrusted into the care of a laundry owner Franciszka Płowa a few months after birth, Banach was brought up by her and by her daughter Maria. In 1902, he entered Gymnasium (secondary school) No.4 in Kraków. On completion of his secondary education in 1910, Banach decided to study engineering in Lvov (Lemberg). He was interested in mathematics but considered it to be a nearly complete science to which very little was left to be added. He decided to study in Lvov, as there was no technical university in Kraków. At the outbreak of World War I, Banach returned to Kraków. He attended some mathematical lectures at the Jagiellonian University and enriched his mathematical knowledge with independent studies.

Wilkosz, born in 1891 in Kraków, was Banach's schoolmate. Endowed with outstanding mathematical and linguistic abilities, he initially linked his future with the latter. However, after two years of philological studies in Kraków, he changed direction to mathematics and studied in Turin. In Italy, he prepared his doctoral dis- 
sertation under the direction of Giuseppe Peano but, due to the outbreak of war, the final exams did not take place and Wilkosz had to return to Kraków. He continued mathematical studies at the Jagiellonian University.

Nikodym was older than his friends. He was born in 1887 in Demycze, a suburb of the small Galician city Zabłotów, to a family with Polish, Czech, Italian and French roots. He graduated in 1911 from the university in Lvov, obtaining the right to teach mathematics and physics in secondary schools. He moved to Kraków and taught in Gymnasium No.4, the same one that Banach and Wilkosz had previously attended. In those days, it was usual that, after graduating university, mathematicians would start off teaching at schools and only after some years would join the university faculty.

\section{Banach after 1916}

Who knows how the future of Banach would have evolved if Steinhaus had not heard the words "Lebesgue integral"? The result of the accidental meeting in the Planty Gardens was many other meetings; Steinhaus had found excellent interlocutors and brilliant mathematicians. In the Autumn of 1917, Steinhaus left Kraków but he did not forget about Banach. Banach and his colleagues continued to deal with mathematics. After Poland regained its independence (the country lost its independence in 1795), the Polish Mathematical Society was formed in the Spring of 1919 in the building at No. 12 St. Anne Street that housed the Mathematics Seminar of the Jagiellonian University. Banach and Nikodym were among the founders (see Figure 2). Stanisław Zaremba became the first president of the society. For more details about the initial period of activity of the Polish Mathematical Society, see [14].

In 1920, Steinhaus was offered a Chair in Mathematics at the university in Lvov, which, in 1919, was given the name Jan Kazimierz University (Jan Kazimierz was the Polish king who founded this university in 1661). Through Steinhaus' intercession, Banach was appointed to an assistantship at Lvov Technical University. In December

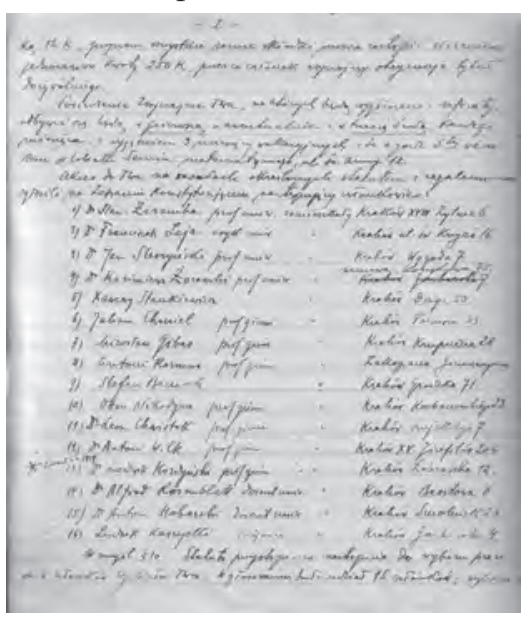

Figure 2. A fragment of the second page of the minutes, with the list of the founders of the Polish Mathematical Society; Banach and Nikodym are listed in positions 9 and 10. (Archives of the Polish Mathematical Society)
1922, Banach was appointed as a professor at the Jan Kazimierz University.

Banach continued research, starting from the work in his $\mathrm{PhD}$ dissertation. This resulted in the great development of functional analysis (the term "functional analysis" only came into use in the 1940s). In 1928, Banach and Steinhaus founded the journal Studia Mathematica. At the end of the 1920s, Banach proved some theorems that are regarded by many authorities as the three basic principles of functional analysis: the Hahn-Banach Theorem, the Banach Closed Graph Theorem and (obtained in collaboration with Steinhaus) the Banach-Steinhaus Theorem. In 1931, Banach's fundamental monograph on functional analysis Teoria operacyj. Operacje linowe (Theory of operations. Linear operations) was published and, one year later, its French translation ([2]) appeared. For a few decades, this monograph was the most fundamental book on functional analysis.

Banach did not only work on functional analysis. For example, he obtained some results in measure theory and the foundations of mathematics. In particular, Banach and Alfred Tarski proved that it is possible to break up a 3D ball into a finite number of pieces that can be recombined to form two balls, each of them congruent to the initial one. The proof relies on the properties of the group $S O(3)$ and the axiom of choice. The theorem is nowadays called the Banach-Tarski Theorem on paradoxical decomposition of the ball.

For more information on Banach, see [7, 9, 11,12]. An excellent description of mathematical results obtained by Banach and his collaborators in Lvov can be found in [10].

In 1939, Lvov was captured by the Soviet Union and, in 1941, Nazi Germans soldiers took Lvov for four years. After World War II, Lvov was joined to the Soviet Union and Banach planned to go to Kraków, where he was offered a Chair at the Jagiellonian University. He died just a few days before the planned move. He is buried in Lychakov Cemetery in Lvov.

Banach published about 80 papers and some monographs and textbooks. It is very interesting that, in the Zentralblatt für Mathematik database, Banach is the mathematician who is most frequently listed in the titles of papers (on 15 April 2017, the score was 23846; the main role played here, of course, is Banach spaces, with a result of 17821).

\section{Nikodym and Wilkosz after 1916}

Wilkosz obtained his PhD from the Jagiellonian University in 1918 and he was later appointed to a chair there. He had a very broad range of mathematical interests. Apart from important scientific results from various branches of mathematics (mathematical analysis, geometry, topology and set theory), he was very active in popularisation and teaching. He wrote about 50 scientific papers and several monographs, textbooks and popular books. In particular, he was an author of the first monograph on topology in Poland ([16]) and the first monograph on topology by a Polish author published abroad ([17]). He was also a pioneer in radio engineering and broadcasting 


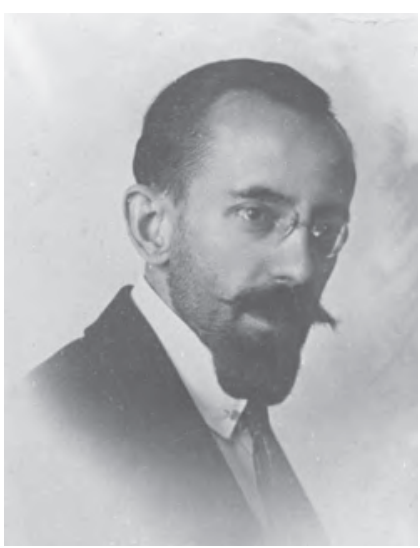

Figure 3. Otton Nikodym in about 1930. (Courtesy of the Mathematical Institute of the Polish Academy of Science)

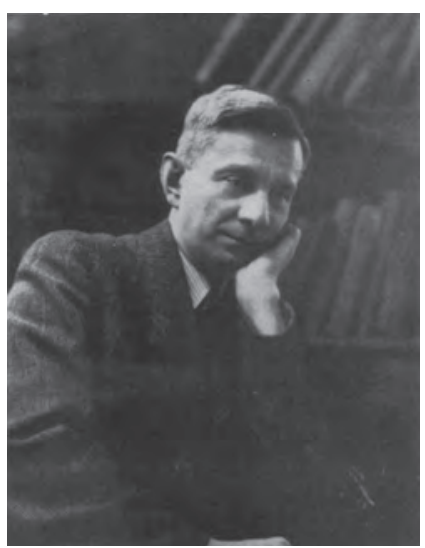

Figure 4. Witold Wilkosz. (Courtesy of the Jagiellonian University). in Poland. He constructed a new radio receiver, known later as "Wilkosz's radio". In the 1920s, he reformed the system of mathematical studies at the Jagiellonian University. He died in 1941 in Kraków.

Nikodym continued teaching in the gymnasium for a few years. He did not endeavour to obtain a PhD. He used to ask: "Will I be wiser because of that?" Nevertheless, he obtained a PhD in 1925 from Warsaw University. Up to World War II, he spent some time in Kraków and some time in Warsaw. In addition to his intensive research, he was writing textbooks and scientific monographs. Manuscripts of two monographs prepared for printing just before the war were lost after the 1944 Warsaw Uprising. He commented: "So I will not have to make corrections" and did not write them again. After World War II, he moved to the USA and continued his research in a wide range of areas, including measure theory and differential equations.

$\mathrm{He}$ is also an author of mathematical results of great importance. Before World War II, he published more than 30 scientific papers and a total of about 100 . One of his most famous results is the Radon-Nikodym Theorem about the existence of a certain measurable function (nowadays often known as the Radon-Nikodym derivative). The result obtained by Nikodym was published in a paper concerning Radon's integral and the version of the theorem obtained by Johann Radon in a special case in 1913 [13]. The theorem is also known as the LebesgueRadon-Nikodym Theorem or the Lebesgue-Nikodym Theorem. Another famous result connected with the name of Nikodym is the Nikodym-Grothendieck Boundedness Theorem. It says that if a family of scalar bounded, finitely additive measures defined on $\sigma$-algebra $A$ is simply bounded then it is uniformly bounded on $A$. The result of Nikodym from the 1930s was generalised about 30 years later by Alexandre Grothendieck.

Nikodym died in 1974 in Utica. In his tomb, there is a mosaic designed by his wife Stanisława, who was a mathematician and an artist. For more information about Nikodym and his wife, see [5, 15].

Nikodym's name also appears frequently in the titles of mathematical papers. According to the Zentralblatt für Mathematik database, his score in the titles of papers

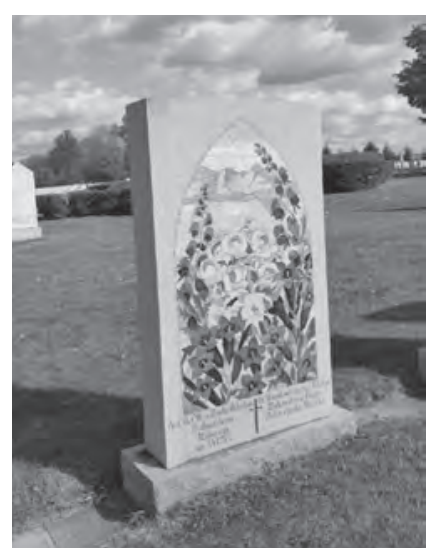

Figure 5. The grave of Otton

Nikodym.

(Photo by Janusz Łysko) is 783 ; he is one of the leading Polish mathematicians in this "competition", with a result similar to those of Sierpiński, Schauder and Marcinkiewicz.

Banach, Nikodym and Wilkosz were invited speakers at the International Congresses of Mathematicians: Nikodym in Bologna in 1928, Wilkosz in Zurich in 1932 and Banach as a plenary speaker at the ICM 1936 in Oslo and an invited speaker in 1928. It is interesting that, although Banach, Nikodym and Wilkosz were good friends and they were discussing mathematics a lot (Banach and Nikodym even worked later on similar areas), any two of them have never written a joint paper.

\section{A monument}

In many cities, statues of people can be seen sitting on benches. Such monuments are now quite popular but is there a better justification for a commemorative bench than the event described here, which had such an effect on science? The concept of placing a bench with a statue of Banach has been considered several times before but the idea has always ended at the concept stage. There are many difficulties, as there are four basic problems to solve:

- Finance. Making such an object would cost a lot and there is no chance of getting any financial support from official sources.

- Permission. Kraków is a historical city, the Planty Gardens are in the city centre and it is extremely difficult to get permission to place a memorial plaque there, let alone a monument. For example, presenting mathematics to a broad audience in the city centre during the $6 \mathrm{ECM}$ immediately caused a reaction from the city guard (see [4]) - fortunately, permission for "maths busking" was then provided (although the formalities took a couple of months).

- Design of the sculpture. Such a monument must be beautiful and representative of the 1916 reality.

- Management of the event. People are needed to manage the project (from the concept until the unveiling of the monument). This is a very troublesome and timeconsuming task.

Many mathematicians have wondered about the precise location of the bench where Steinhaus encountered Banach? The Planty Gardens is a large park of about 21 hectares surrounding the historical centre of Kraków. The meeting could have happened in many different places. In his memoirs and articles about Banach, Steinhaus does not indicate a precise place. However, after careful analysis of the problem, we came to a conclu- 
sion. Of course, one cannot be sure but it is almost certain that this meeting happened at the extreme end of the Planty Gardens, close to Wawel Castle and the house where Banach lived (for details, see [6]). Thus, there was a renewed motivation for making a bench memorialising this significant event. Moreover, the 100th anniversary of the event was approaching.

In 2014, the Dean of the Faculty of Mathematics and Computer Science of the Jagiellonian University appointed a special committee to act upon the creation of the bench. It consisted of seven people: Artur Birczyński, Danuta Ciesielska, Krzysztof Ciesielski (chair), Małgorzata Jantos, Jerzy Ombach, Piotr Tworzewski and Karol Życzkowski. Our idea was to present not only Banach but Nikodym as well, sitting on a bench as it was in 1916. And now, everyone can come to them and join them like Steinhaus did.

Stefan Dousa, an outstanding Polish sculptor, agreed to design the monument. Dousa is a professor at the Kraków University of Technology and a creator of many of the magnificent monuments, plaques and medals in Poland, as well as many European countries and the USA. Moreover, Dousa likes mathematicians. He had already made a memorable medal for the 6ECM (see [8]). We got all the required permissions from the city authorities (with great help from M. Jantos, who is a member of the City Council). One of the good reasons that permission was granted was that, in this case, a monument in the form of figures on a bench was perfectly justified. Finally, a sponsor was found. ASTOR, a company that provides modern technologies in the fields of industrial robotics, IT solutions and technical knowledge through training and consulting, agreed to finance the monument. The name ASTOR is an acronym for Automatyka, Sterowanie, Transmisja, Oprogramowanie, Robotyka (Automation, Control, Transmission, Software, Robotics).

\section{Unveiling}

It was known in what area of the Planty Gardens the bench should be placed and it was Stefan Dousa who picked the final location of the bronze monument. It is on the way from Wawel Castle to the Main Square, the route most frequently used by tourists. The unveiling was

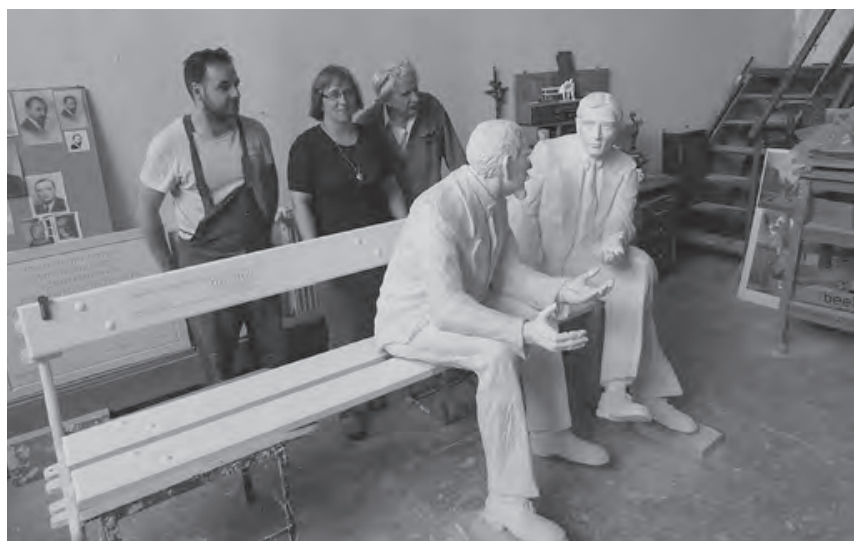

Figure 6. From left to right: Piotr Idzi (Dousa's assistant),

D. Ciesielska and S. Dousa in Dousa's workplace and a plaster model of a monument.

planned not for the Summer (the exact date of the historic meeting is unknown but it is known that it was in the Summer) but in October, after the start of the academic year. The celebration took place on 14 October 2016. More than 200 people attended, including many high profile guests. Several of them came from abroad. Some members of the Council of the European Mathematical Society and authorities of the Polish Mathematical Society were also present. The monument was unveiled by Stanisław Kistryn (Vice-Rector of the Jagiellonian University), Stefan Życzkowski (President of ASTOR), Monika Waksmundzka-Hajnos from Lublin (a niece of Banach) and Banach's nephew, John Greczek from the USA. The film of the ceremony can be seen at https://www.youtube.com/watch?v=813R1905hUc. After the ceremony, the guests visited the ASTOR Innovation Room and were invited for dinner in the CK Browar Restaurant. The choice of this location was because the restaurant is in the basement of the building where Gymnasium No.4 was located 100 years ago.

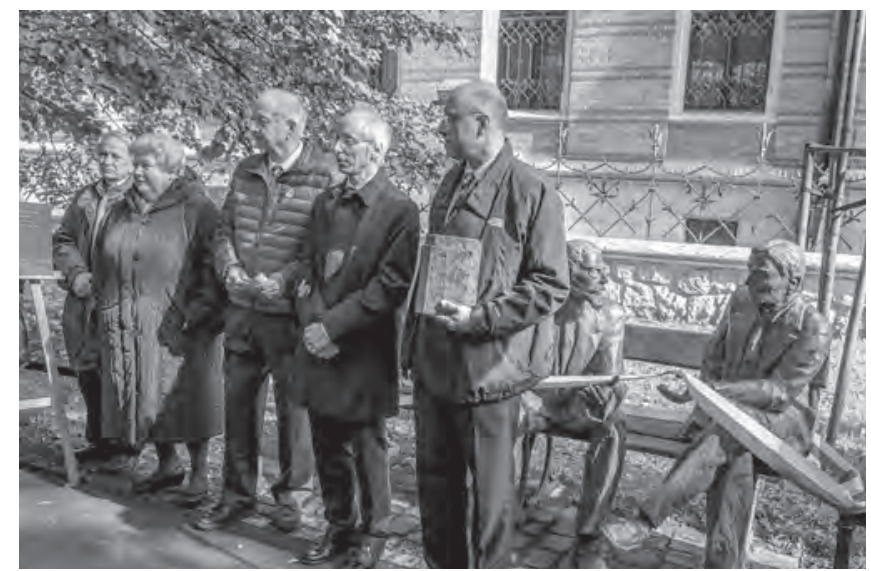

Figure 7. The unveiling of the bench. From left to right: S. Dousa, M. Waksmundzka-Hajnos, J. Greczek, S. Kistryn and S. Życzkowski. (Courtesy of the Jagiellonian University)

In addition to the figures sitting on the bench, the backrest of the bench is enscribed with the logo of ASTOR and the inscription: "On the 100th anniversary of the most famous mathematical discussion at the Planty Gardens." On the seat of the bench, next to the figures, mathematical symbols are carved. We decided that they would not be symbols of Banach's and Nikodym's best-known results but, instead, a formula from the paper in which the solution of the problem communicated by Steinhaus to Banach at their first meeting was published [3].

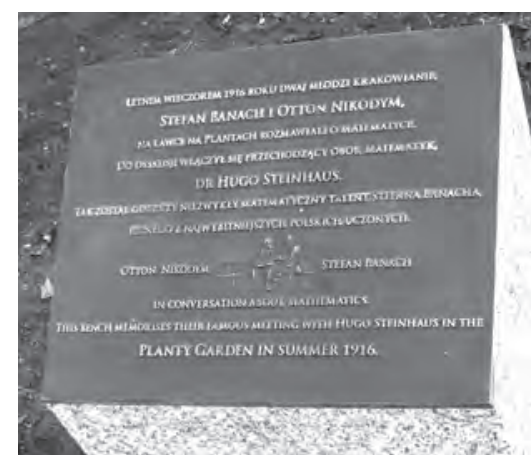

Figure 8. The plaque close to the bench.
Moreover, close to the bench, there is a special plaque (see Fig. 8) with information (in Polish and English) about the event in 1916 and the figures.

Now, visiting the Planty Gardens in this area, one can see that the bench is of 


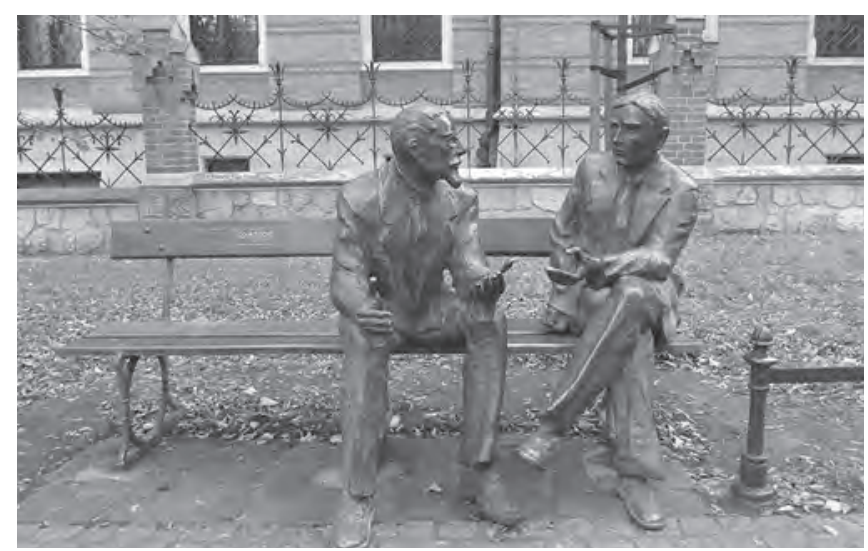

Figure 9. The bench.

great interest. People often sit on it, take photographs with Banach and Nikodym, study the inscriptions, etc. It is really a great promotion of mathematics. Moreover, the bench is really marvellous and perfectly made by Dousa. The faces of Banach and Nikodym are very similar to their photographs dated 100 years ago. As one approaches the bench, it almost looks as if there were two real human beings talking to each other.

One mathematician, after a first look at the bench, commented: "It is obvious that they talk about mathematics."

\section{References}

[1] S. Banach. Sur les opérations dans les ensembles abstraits et leur application aux équations intégrales. Fundamenta Mathematicae, 3: 133-181, 1922.

[2] S. Banach. Théorie des opérations linéaires. Monografie Matematyczne 1, Warszawa, 1932.

[3] S. Banach and H. Steinhaus. Sur la convergence en moyenne de séries de Fourier. Bull. Inter. de l'Acad. Sciences de Cracovie, Séries A, Sciences Mathématiques, pages 87-96, 1918.

[4] E. Behrends. Mathematics in the streets of Kraków. EMS Newsletter, 85: 20-21, 2012.

[5] D. Ciesielska. A mathematician and a painter Stanisława Nikodym and her husband Otton Nikodym. Oberwolfach Reports, 2/2017: 33-36, 2017.
[6] D. Ciesielska and K. Ciesielski. Banach in Kraków: a case reopened. Math. Intelligencer, 35(3): 64-68, 2013.

[7] K. Ciesielski. On Stefan Banach and some of his results. Banach Journal of Mathematical Analysis, 1(1): 1-10, 2007.

[8] K. Ciesielski. The 6ECM Medal. EMS Newsletter, 86: 18, 2012.

[9] R. Duda. Facts and myths about Stefan Banach. EMS Newsletter, 34: 29-34, 2009.

[10]R. Duda. Pearls from a lost city: The Lvov School of Mathematics. Birkhäuser, 2014.

[11]E. Jakimowicz and A. Miranowicz (eds.). Stefan Banach. Remarkable life, brilliant mathematics. Gdańsk University Press, 2010.

[12]R. Kałuża. Through a reporter's eyes. The life of Stefan Banach. Birkhäuser, 1996.

[13] O. Nikodym. Sur une généralisation des intégrales de M.J. Radon. Fundamenta Mathematicae, 15: 131-179,1930.

[14] J. Piórek. From the minutes of the Mathematical Society in Cracow. EMS Newsletter, 32: 17-18, 1999.

[15] W. Szymański. Who was Otto Nikodym? Math. Intelligencer, 12(2): 27-31, 1990.

[16]W. Wilkosz. Podstawy ogólnej teorji mnogości. Trzaska, Evert \& Michalski, 1921.

[17] W. Wilkosz. Les propriétés topologiques du plan euclidien. Gauthier-Villars, 1931.

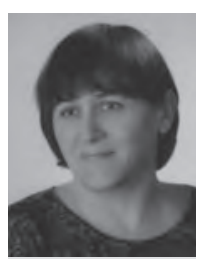

Danuta Ciesielska[smciesie@cyfronet.krakow.pl] is a mathematician and an historian of science. She is a Section Editor of the journal "Antiquitates Mathematicae" of the Polish Mathematical Society, which is devoted to the history of mathematics. She is a member of the Commission on the History of Science of the Polish Academy of Arts and Sciences.

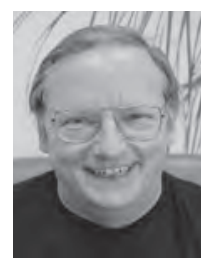

Krzysztof Ciesielski [krzysztof.ciesielski@ im.uj.edu.pl] was an Associate Editor of the EMS Newsletter, 1999-2012, and a member of the Raising Public Awareness of Mathematics Committee of the EMS, 2009-2016. He is currently an Associate Editor of the journal "Wiadomości Matematyczne" of the Polish Mathematical Society. 